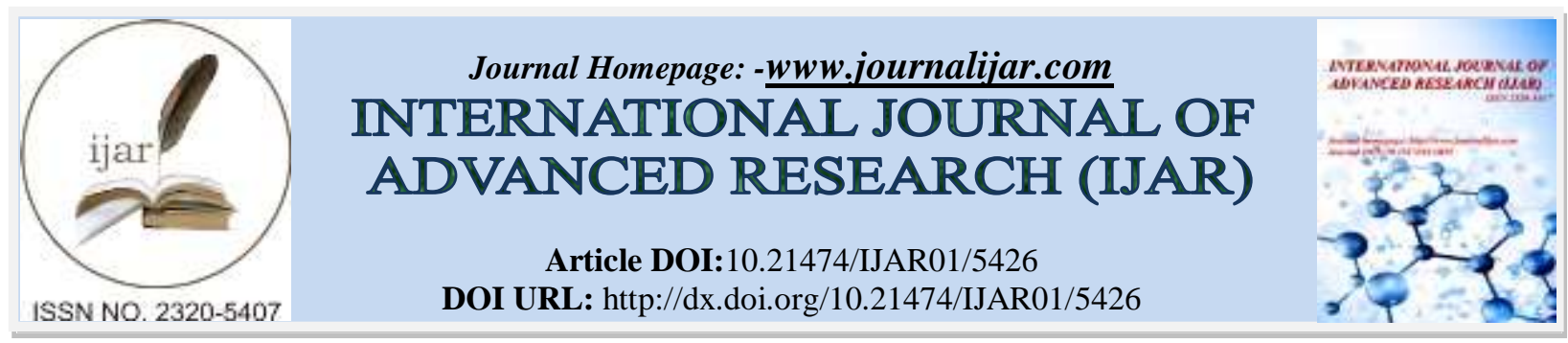

RESEARCH ARTICLE

\title{
DELPHI METHOD: A WARFARE TECHNIQUE USED IN RESEARCH WITH MODERN METHODS OF COMMUNICATION.
}

Vijayasree Seelam.

Dept.of Library \& Information Science, University College,Kakatiya University.

\section{Manuscript Info}

Manuscript History

Received: 14 July 2017

Final Accepted: 16 August 2017

Published: September 2017

Key words:-

Communication,feedback,

forecasting

\section{Abstract}

Delphi method is well developed and easily communicated feedback method used in reasearch and buisiness for forecasting. In the era of communication the method is verymuch convinient to get the information and feedback as quick and reliable.the disadvanages are very meagre. the method and its advantages and disadvantages applicability in modern communication era is discussed in this paper

Copy Right, IJAR, 2017,. All rights reserved.

\section{Introduction:-}

The Delphi technique, mainly developed by Dalkey and Helmer at RAND Corporation. This technique was developed at the beginning of cold war to forecast the impact of technology on warfare. Henry H.Arnold ordered the creation of the report for the U.S. Army Air corps on the future technological capabilities that might be used by the military. The Delphi method is a structured communication technique, originally developed as a systematic, interactive forecasting method which relies on a panel of experts.

\section{Definition:-}

According to Busha and Harter:-

"Delphi method comprises a group of modified survey procedures, designed for use in refining the judgmental data collected from a panel of selected experts."

According to Dietz:-

"when responses begin to stabilize across iterations or when resources are exhausted, the results of the final round are used as the forecasts produced by the study."

\section{Objectives:-}

1. To determine or develop a range of possible programme alternatives.

2. To explore or expose underlying assumptions or information leading to difficult judgment.

3. To seek out information which may generate a consensus on the part of the respondent group.

4. To correlate informed judgments on a topic spanning a wide range of disciplines.

5. To educate the respondent group as to the diverse and interrelated aspects of the topic.

Benefit of this research method include the systematic way in which a wide reservoir of knowledge, experience and expertise can be drawn upon instead of relying on adhoc communications with selected individual. 


\section{Features:-}

1. Anonymity

2. Controlled feedback

3. Statistical group response

4. Expert input

Process of delphi method:-

The experts answer questionnaires in two or more rounds. After each round, a facilitator provides an anonymous summary of the experts forecasts from the previous round as well as the reasons they provided for their judgments. Thus, experts are encouraged to revise their earlier answers in light of the replies of other members of their panel. It is believed that during this process the range of the answers will decrease and the group will converge towards the "correct" answer. Finally, the process is stopped after a pre-defined stop criterion (e.g. number of rounds, achievement of consensus, stability of results) and the mean or median scores of the final rounds determine the results.Delphi is based on the principle that forecasts (or decisions) from a structured group of individuals are more accurate than those from unstructured groups. The technique can also be adapted for use in face-to-face meetings, and is then called mini-Delphi or Estimate-Talk-Estimate (ETE).

\section{Steps involved in the method:-}

1. Define the problem

2. Give everyone the problem

3. Collate the problem

4. Give everyone the collection

5. Repeat as necessary

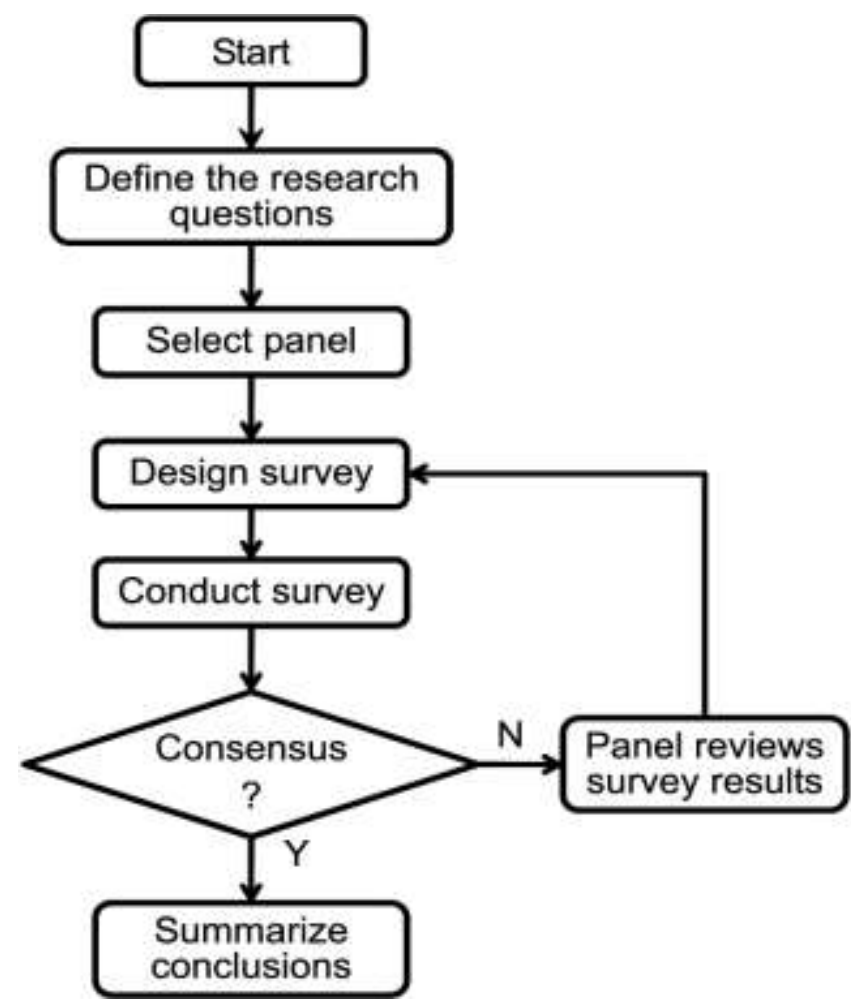

\section{Advantages:-}

1. Opportunities for large number of people to participate.

2. Focus is on ideas rather than individuals.

3. Anonymity for participants which make contributions of ides a safe activity.

4. Opportunities for participants to reconsider their opinions.

5. Allows for identification of priorities. 


\section{Disadvantages:-}

1. Large amount of time to conduct several rounds of servey.

2. Complexity of data analysis.

3. The difficulty of maintaing participant enthusiasm throughout process.

4. The problem of keeping statements value free and clearly defined.

5. Self reporting data is subject to respondents biases and memories.

6. The bandwagon effect of a majority opinion.

Delphi method in Library and Information science:-

In library and information science,Delphi method was used by library research unit, university of California ,Los angeles. It was one of the most ambitious projects to study the future of library education in US.

\section{Delphi method with modern communication techniques:-}

The method is involved in good feedback from various stakeholders and many number of times,so using the modern techniques of communication like E-Mail,FAX,MESSENGER like informtion technology can be now used to save time and accuracy

\section{Conclusion:-}

During the last ten years,the Delphi method was used more often especially for national science \& technology foresight. Some modifications and methodological improvements have been made mean while.Nevertheless,one has to be aware of the strengths and weakness of the method so that it cannot be applied in every case. Delphi method has been widely used for business forecasting and has certain advantages over another structured forecasting approach, prediction markets.

\section{References:-}

1. Norman Dalkey, Olaf Helmer (1963) An Experimental Application of the Delphi Method to the use of experts. Management Science, 9(3), Apr 1963, pp 458-467

2. Charles H. Busha,Stephen P. Harter (1980) Research methods in librarianship: techniques and interpretationAcademic Press, 28 Haz 1980

3. Thomas Dietz(1987) Methods for analyzing data from Delphi panels: Some evidence from a forecasting study . Technological forecasting and social change 31(1)March 1987, pp79-85 